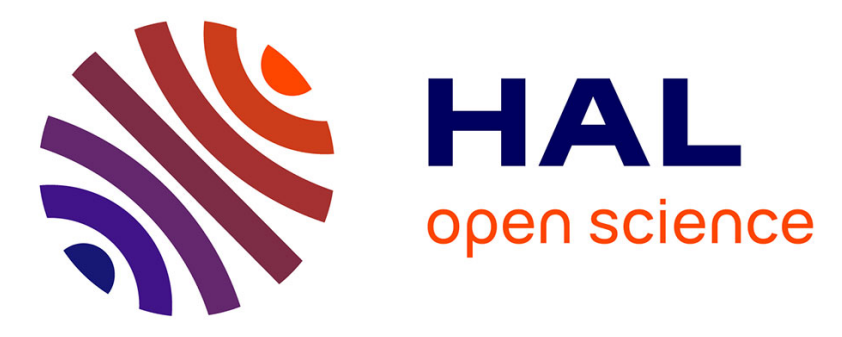

\title{
Polymorphisms in resulting in aberrant codon-usage and their analysis on familial breast cancer risk
}

\author{
Rongxi Yang, Bowang Chen, Kari Hemminki, Barbara Wappenschmidt, \\ Christoph Engel, Christian Sutter, Nina Ditsch, Bernhard H. F. Weber, Dieter \\ Niederacher, Norbert Arnold, et al.
}

\section{To cite this version:}

Rongxi Yang, Bowang Chen, Kari Hemminki, Barbara Wappenschmidt, Christoph Engel, et al.. Polymorphisms in resulting in aberrant codon-usage and their analysis on familial breast cancer risk. Breast Cancer Research and Treatment, 2009, 118 (2), pp.407-413. 10.1007/s10549-009-0348-7 . hal00535343

\section{HAL Id: hal-00535343 \\ https://hal.science/hal-00535343}

Submitted on 11 Nov 2010

HAL is a multi-disciplinary open access archive for the deposit and dissemination of scientific research documents, whether they are published or not. The documents may come from teaching and research institutions in France or abroad, or from public or private research centers.
L'archive ouverte pluridisciplinaire HAL, est destinée au dépôt et à la diffusion de documents scientifiques de niveau recherche, publiés ou non, émanant des établissements d'enseignement et de recherche français ou étrangers, des laboratoires publics ou privés. 


\title{
Polymorphisms in $B R C A 2$ resulting in aberrant codon-usage and their analysis on familial breast cancer risk
}

\author{
Rongxi Yang • Bowang Chen · Kari Hemminki · Barbara Wappenschmidt • \\ Christoph Engel - Christian Sutter · Nina Ditsch - Bernhard H. F. Weber · \\ Dieter Niederacher - Norbert Arnold • Alfons Meindl - Claus R. Bartram • \\ Rita K. Schmutzler · Barbara Burwinkel
}

Received: 8 January 2009/Accepted: 11 February 2009/Published online: 20 February 2009

(C) Springer Science+Business Media, LLC. 2009

\begin{abstract}
Mutations in BRCA1 and BRCA2 are associated with increased breast cancer risk. While numerous nonsynonymous SNPs in BRCAl/2 have been investigated for breast cancer risk, the impact of synonymous SNPs has not been studied so far. Recently, it has been reported that synonymous SNPs leading to an aberration from the preferred codon-usage can have functional effects and consequently be associated with disease. This motivated us to search for SNPs
\end{abstract}

\section{R. Yang $(\bowtie) \cdot$ B. Burwinkel}

Helmholtz-University Group Molecular Epidemiology, German

Cancer Research Center (DKFZ), Im Neuenheimer Feld 581,

69120 Heidelberg, Germany

e-mail: r.yang@dkfz.de

R. Yang · B. Burwinkel

Division Molecular Biology of Breast Cancer, Department

of Gynecology and Obstetrics, University of Heidelberg,

69120 Heidelberg, Germany

B. Chen · K. Hemminki

Division of Molecular Genetic Epidemiology, German Cancer

Research Center (DKFZ), Im Neuenheimer Feld 580,

69120 Heidelberg, Germany

K. Hemminki

Department of Biosciences at Novum, Karolinska Institute, 14157 Huddinge, Sweden

B. Wappenschmidt $\cdot$ R. K. Schmutzler

Division of Molecular Gynaeco-Oncology, Department of Gynaecology and Obstetrics, Clinical Center University

of Cologne, 50931 Köln, Germany

B. Wappenschmidt · R. K. Schmutzler

Center of Molecular Medicine Cologne (CMMC),

University Hospital of Cologne, 50931 Köln, Germany

C. Engel

Department of Medical Informatics, Statistics and Epidemiology,

University of Leipzig, 04107 Leipzig, Germany with the tendency to differential codon-usage in BRCAl/ $B R C A 2$. Based on defined criteria, two codon-usagechanging variants, Ser455Ser $(1365 \mathrm{~A}>\mathrm{G})$ and Ser2414Ser $(7242 \mathrm{~A}>\mathrm{G})$, were detected in $B R C A 2$, whereas no such variant could be identified in BRCA1. We investigated the impact of these variants on breast cancer risk in a large casecontrol study. However, both SNPs, BRCA2 Ser2414Ser $(7242 \mathrm{~A}>\mathrm{G})$ and Ser455Ser $(1365 \mathrm{~A}>\mathrm{G})$, showed no

C. Sutter - C. R. Bartram

Institute of Human Genetics, University of Heidelberg, 69120 Heidelberg, Germany

N. Ditsch

Department for Obstetrics and Gynaecology, Ludwig

Maximilians Universität, Marchionini Str. 15, 81377 Munich,

Germany

B. H. F. Weber

Institute of Human Genetics, University of Regensburg,

93053 Regensburg, Germany

D. Niederacher

Division of Molecular Genetics, Department of Gynaecology and Obstetrics, Clinical Center University of Düsseldorf, 40225 Düsseldorf, Germany

N. Arnold

Division of Oncology, Department of Gynaecology and Obstetrics, University Hospital Schleswig-Holstein, 24105 Kiel, Germany

A. Meindl

Department of Gynaecology and Obstetrics, Klinikum rechts der Isar, Technical University of Munich, 81675 Munich, Germany 
association with breast cancer risk. This indicates that these codon-usage-changing SNPs have no major impact on familial breast cancer risk.

Keywords Breast cancer risk - Case-control study · Codon-usage $\cdot B R C A 1 \cdot B R C A 2$

\section{Introduction}

Breast cancer is the most frequent cancer in women, and after lung cancer the second most frequent cancer in the world [1]. Up to $10 \%$ of women who are diagnosed with breast cancer report a family history [2, 3]. A large twin and family study has shown that inherited genetic factors account for about $28 \%$ of all breast cancers, while the remaining cases are due to shared or non-shared environmental factors [4, 5]. Furthermore, familial aggregation of breast cancer suggests a major contribution of hereditable genetic factors $[6,7]$.

Several genes contribute to familial breast cancer risk. Among them, the breast cancer 1 gene (BRCAl) and breast cancer 2 gene (BRCA2) are the most important ones. Mutations in these genes confer a high-penetrance and account for about 5-30\% of familial breast cancer cases [8-10]. Missense mutations, intronic variants and in-frame deletions or insertions in either BRCA1 or BRCA2 confer a lifetime risk of breast cancer from 60 to $85 \%$ [11-14]. The risk of $B R C A 1$ and $B R C A 2$ mutation carriers can be further modified by other genetic or environmental factors [15-18].

It has been suggested that a single nucleotide polymorphism (SNP) can alter the amino acid residue in the primary protein sequence and consequently impact on protein folding, target recognition, transcription regulation and even the long-range enhancer regulation [19-22]. Thus, some SNPs could affect the disease processes and clinic response [23, 24]. However, these studies mainly focused on the non-synonymous SNPs, whereas the effects of synonymous SNPs are largely unknown.

Recently, Chava Kimchi-Sarfaty et al. [25] reported a synonymous SNP in the Multidrug Resistance 1 (MDR1) gene leading to an aberration from the preferred codonusage. An ATC-codon (20.9\% usage) is changed to an ATT-codon (15.8\% usage). As a result, the use of the less preferred codon appears to influence the translation rate, which in turn affects protein folding and finally leads to altered drug and inhibitor interaction, although the mRNA and protein levels are similar to the wild-type [25, 26]. Consequently, this SNP has been found to be associated with MDR1 activity in B-cell chronic lymphocytic leukaemia [27]. One of the most recent works reported a synonymous SNP in beta-arrestin 2, which suggested that the rare codon AGT is associated with increased risk of Tardive dyskinesia occurrence [28]. A silent mutation was also found by Knobe et al. [29] in five of total 86 families with haemophilia B in Sweden. This SNP is also an aberration from the preferred codon-usage (GTG 28.2\% usage to GTA $7.1 \%$ usage) [29]. Anton A. Komar suggested that infrequent codons in mRNA appear to be slowly translated, whereas frequent codons are rapidly translated [30]. Thus, the use of rare codons influences the translation rate of mRNA, which consecutively affects protein folding secondary structure [31-33]. Furthermore, amino acids encoded by GC third bases appear to be more preferred to cell function and survival than those encoded by AT third bases [34, 35], indicating that the codon-usage might be one of the possible explanations for the bias of the alleles in synonymous SNPs. Other reports have suggested that synonymous SNPs can also affect the stability of mRNA or protecting from deleterious mutations [36, 37].

In the present study, we investigated whether there are synonymous polymorphisms in BRCA1 and BRCA2 with less preferred codon-usage and consequently whether these SNPs could be associated with an increased breast cancer risk.

\section{Materials and methods}

\section{Study population}

The database of the German consortium for hereditary breast and ovarian cancer (GC-HBOC), which comprises indentified polymorphisms and variants of 3,564 analysed BRCA1/BRCA2 mutation-negative familial breast cancer index cases, was used to select for silent SNPs. These SNPs were further investigated for an alteration of the preferred codon-usage in Homo sapiens and within the BRCA1/2 genes by comparison with the codon-usage database (http://www.kazusa.or.jp/codon).

Genotyping was performed on genomic DNA of BRCA1/2 mutation-negative index patients from $811 \mathrm{Ger}$ man breast cancer (BC) families, among them a subset of 351 high-risk breast cancer cases (A1 group: families with two or more cases of breast cancer including at least two cases with onset of the disease under the age of 50 years; B group: families with one or more male breast cancer cases), and 1,330 unrelated healthy German women. The breast cancer cases are comprised of unrelated women that had been tested $B R C A 1 / 2$ mutation-negative by applying the denaturing high performance liquid chromatography (DHPLC) method on all exons, followed by direct sequencing of conspicuous exons [8]. The BC samples were collected during the years 1997-2007 by three centres of the German Consortium for Hereditary Breast and Ovarian Cancer 
(centres of Heidelberg, Cologne and Munich, see authors' affiliations). Index patients were first diagnosed with breast cancer and then referred to a family registry. All breast cancer patients gave an informed consent for the study.

The control population included healthy and unrelated female blood donors collected by the German Red Cross Blood Service of Baden-Wuerttemberg-Hessia and Institute of Transfusion Medicine and Immunology (Mannheim), sharing the same ethnic background as the breast cancer patients. The age distribution in controls and cases is similar (controls: mean age 43.9 years, median age 42 years, age from 18 to 68 years old; cases: mean age 45.4 years, median age 45 years, age from 19 to 87 years old). According to the German guidelines for blood donation, all blood donors were examined by a standard questionnaire and gave their informed consent. They were randomly selected during the years 2004-2007 for this study and no further inclusion criteria were applied during recruitment. This study was approved by the Ethics Committee of the University of Heidelberg (Heidelberg, Germany).

\section{Genotyping}

Two SNPs in BRCA2, Ser455Ser $(1365 \mathrm{~A}>\mathrm{G})$ and Ser2414Ser $(7242 \mathrm{~A}>\mathrm{G})$, were selected from the GC-HBOC database following defined criteria described in the discussion section. These SNPs were analysed using TaqMan allelic discrimination assays according to earlier descriptions [38]. Sequences of primers and probes are available upon request. The SNP assays were validated by re-genotyping $10 \%$ of all samples.

\section{Statistical analysis}

Hardy-Weinberg equilibrium test was undertaken using the $\chi^{2}$ 'goodness-of-fit' test by a tool from the Institute of Human Genetics, Technical University Munich, Munich, Germany (http://ihg.gsf.de/cgi-bin/hw/hwa1.pl). Genotypespecific odds ratios (OR), 95\% confidence intervals (CI) and $P$ values were computed by unconditional logistic regression using SAS version 9.1 (SAS Institute Inc, Cary, NC). Age, treated as a continuous variable was included in the regression as covariate. $P$ values were calculated using two-sided $\chi^{2}$ test. The power $(\alpha=0.05)$ was calculated using the power and sample size calculation software PS version 2.1.31 (http://www.mc.vanderbilt.edu/prevmed/ps/ index.htm) [39]. SNPs linked with Ser455Ser and Ser2414Ser with $r^{2} \geq 0.8$ and block definition were identified using HaploView version 3.32 (http://www.broad.mit.edu/mpg/ haploview). The linked SNPs' breast cancer associations were further checked if they have being analysed in the Cancer Genetic Markers of Susceptibility genome wide association study (CGEMS) (https://caintegrator.nci.nih. gov/cgems/browseSetup.do).

\section{Results}

We searched for SNPs in BRCA1 and BRAC2 leading to a less preferred codon-usage in familial breast cancer patients, by investigating the database of the German consortium for hereditary breast and ovarian cancer (GCHBOC). This database included genetic variations indentified in 3564 BRCA1/2 mutation-negative index familial breast cancer cases.

From this database, seven synonymous variations were found in BRCAl and nine synonymous variations were found in BRCA2. Some of these synonymous SNPs were also detected by Loizidou et al. [40]. We selected the most interesting candidates by applying the following criteria. The SNP induces a reduction of codon-usage of more than $50 \%$ investigating the general codon-usage in Homo saklpiens. Furthermore, the allele frequency should be larger than $1 \%$ (Table 1). Using these criteria, no such variants in $B R C A 1$ but two variants in BRCA2, Ser455Ser $(1365 \mathrm{~A}>\mathrm{G})$ and Ser2414Ser (7242A $>$ G) (Table 1) could be identified. These two SNPs were reported by Loizidou $\mathrm{M}$ et al. but with limited samples' investigation [40]. Thus, we investigated the impact of these two variants on breast cancer risk performing a large case-control study on familial BRCA1/2 mutation-negative breast cancer cases and controls.

The genotype analysis of BRCA2 Ser455Ser (1365A > G) and Ser2414Ser (7242A $>$ G) was performed on genomic DNA of BRCA1/2 mutation-negative index patients of 811 German breast cancer families with a mean age of 45 years, and 1,330 unrelated German control individuals with a mean age of 44 years. Genotype distribution in both controls and cases were consistent with the Hardy-Weinberg equilibrium (HWE). The SNP assays were validated by re-genotyping $10 \%$ of all samples attaining concordance rates of more than $99.5 \%$ for both investigated SNPs.

Allele and genotype frequencies of BRCA2 Ser2414Ser $(7242 \mathrm{~A}>\mathrm{G})$ and $\operatorname{Ser} 455 \operatorname{Ser}(1365 \mathrm{~A}>\mathrm{G})$ were similar between familial breast cancer cases and controls. Ser2414Ser $(7242 \mathrm{~A}>\mathrm{G})([\mathrm{G}]$ vs. $[\mathrm{A}], \mathrm{OR}=1.00,95 \%$ CI $0.86-1.17$, $P=1.00 ;$ [AG] vs. [AA], OR $=1.01,95 \%$ CI $0.83-1.22$, $P=0.96$; [GG] vs. [AA], OR $=1.00,95 \%$ CI $0.83-1.21$, $P=0.98 ; P_{\text {trend }}=1.00$, Table 2$)$ and Ser455Ser $(1365 \mathrm{~A}>$ G) ([G] vs. $[\mathrm{A}], \mathrm{OR}=0.94,95 \%$ CI $0.65-1.37, P=0.76$; [AG] vs. [AA], OR $=1.02,95 \%$ CI $0.69-1.50, P=0.92$; $P_{\text {trend }}=0.76$, Table 2 ), showing no association with familial breast cancer. We also analysed if individuals carrying the rare allele in both SNPs versus homozygous wild-type carriers in both SNPs are more frequent in cases than in controls, but did not find any significant association $(P=0.16$, data not show). 
Table 1 Codon usage alternation in $B R C A 1 / 2$ synonymous variations

\begin{tabular}{|c|c|c|c|c|}
\hline Variant & Consequence & Numbe $^{\mathrm{a}}$ & Codon change & $\begin{array}{l}\text { Homo sapiens } \\
\text { codon-usage alteration }\end{array}$ \\
\hline BRCA1 A5A $(15 \mathrm{~T}>\mathrm{C})$ & Synonymous & 71 & $\mathrm{GCT}>\mathrm{GCC}$ & $18.4>27.7$ \\
\hline BRCA1 C197C $(591 \mathrm{C}>\mathrm{T})$ & Synonymous & 9 & TGC $>$ TGT & $12.6>10.6$ \\
\hline BRCA1 P359P (1077A > G) & Synonymous & 8 & $\mathrm{CCA}>\mathrm{CCG}$ & $16.9>6.9$ \\
\hline BRCA1 S694S $(2082 \mathrm{C}>\mathrm{T})$ & Synonymous & 1,079 & $\mathrm{AGC}>\mathrm{AGT}$ & $19.5>12.1$ \\
\hline BRCA1 L771L (2313T > C) & Synonymous & 1,070 & $\mathrm{CTT}>\mathrm{CTC}$ & $13.2>19.6$ \\
\hline BRCA1 S1436S $(4308 \mathrm{~T}>\mathrm{C})$ & Synonymous & 1,073 & $\mathrm{TCT}>\mathrm{TCC}$ & $15.2>17.7$ \\
\hline BRCA1 Q1604Q (4812A > G) & Synonymous & 4 & $\mathrm{CAA}>\mathrm{CAG}$ & $12.3>34.2$ \\
\hline BRCA2 S455S $(1365 \mathrm{~A}>\mathrm{G})$ & Synonymous & 116 & TCA $>$ TCG & $12.2>4.4$ \\
\hline BRCA2 H743H $(2229 \mathrm{~T}>\mathrm{C})$ & Synonymous & 115 & $\mathrm{CAT}>\mathrm{CAC}$ & $10.9>15.1$ \\
\hline BRCA2 Q961Q $(2883 \mathrm{G}>\mathrm{A})$ & Synonymous & 0 & $\mathrm{CAG}>\mathrm{CAA}$ & $34.2>12.3$ \\
\hline BRCA2 K1132 K (3396A > G) & Synonymous & 898 & AAA $>$ AAG & $24.4>31.9$ \\
\hline BRCA2 S1172S (3516G > A) & Synonymous & 9 & TCG $>$ TCA & $4.4>12.2$ \\
\hline BRCA2 V1269 V (3807T > C) & Synonymous & 690 & GTT > GTC & $11.0>14.5$ \\
\hline BRCA2 L1356L $(4068 \mathrm{G}>\mathrm{A})$ & Synonymous & 18 & TTG $>$ TTA & $12.9>7.7$ \\
\hline BRCA2 S1733S $(5199 \mathrm{C}>\mathrm{T})$ & Synonymous & 45 & $\mathrm{TCC}>\mathrm{TCT}$ & $17.7>15.2$ \\
\hline BRCA2 S2414S (7242A > G) & Synonymous & 727 & TCA $>$ TCG & $12.2>4.4$ \\
\hline
\end{tabular}

Table 2 Genotype frequencies of codon-usage-changing SNPs in BRCA2

\begin{tabular}{|c|c|c|c|c|c|c|}
\hline SNP & Genotypes & Case $(\%)$ & Control (\%) & OR & $95 \%$ CI & $P$ \\
\hline & AA & 747 (94.4) & $1,229(94.1)$ & 1 & & \\
\hline$B R C A 2$ & AG & $44(5.6)$ & $74(5.7)$ & 1.021 & $0.694-1.502$ & 0.916 \\
\hline Ser455Ser & GG & $0(0.0)$ & $3(0.2)$ & - & - & 0.977 \\
\hline $1365 \mathrm{~A}>\mathrm{G}$ & [G] vs. [A] & & & 0.942 & $0.648-1.370$ & 0.755 \\
\hline \multirow[t]{2}{*}{ rs1801439 } & & & & & & $P_{\text {trend }}=0.758^{\mathrm{a}}$ \\
\hline & AA & 483 (61.5) & $815(62.2)$ & 1 & & \\
\hline$B R C A 2$ & AG & $262(33.4)$ & $431(32.9)$ & 1.005 & $0.829-1.218$ & 0.960 \\
\hline Ser2414Ser & GG & $40(5.1)$ & $64(4.9)$ & 1.003 & $0.834-1.205$ & 0.978 \\
\hline $7242 A>G$ & [G] vs. [A] & & & 1.000 & $0.857-1.166$ & 0.999 \\
\hline rs1799955 & & & & & & $P_{\text {trend }}=0.999^{\mathrm{a}}$ \\
\hline
\end{tabular}

Adjusted for age; all analyses done with SAS Version 9.1 Proc Logistic

${ }^{\text {a }} \chi^{2}$ test for trend

The two SNPs in BRCA2, Ser455Ser $(1365 \mathrm{~A}>\mathrm{G})$ and Ser2414 $(7242 A>G)$, were found to be not in linkage disequilibrium to each other $\left(r^{2}=0.0090\right)$. Furthermore, a haplotype analysis was performed and investigated for a putative association with breast cancer risk. As a result, none of the three haplotypes (rs1801439-rs1799955: A-A, A-G and $\mathrm{G}-\mathrm{A}$ ) of the two polymorphisms revealed any association with breast cancer risk (data not shown). To compare our results with findings from genome wide studies, we analysed $200 \mathrm{~kb}$ flanking regions of $B R C A 2$ Ser455Ser $(1365 A>G)$ and Ser2414Ser $(7242 A>G)$, which covers the whole BRCA2 gene. Neither of the SNPs, Ser455Ser $(1365 \mathrm{~A}>\mathrm{G})$ and $\operatorname{Ser} 2414 \operatorname{Ser}(7242 \mathrm{~A}>\mathrm{G})$ themselves, nor SNPs in linkage disequilibrium with Ser2414Ser $\left(r^{2} \geq 0.9\right)$ have been analysed in the Cancer
Genetic Markers of Susceptibility genome wide association study (CGEMS) (https://caintegrator.nci.nih.gov/cgems/ browseSetup.do). However, one SNP in linkage disequilibrium with Ser455Ser (1365A > G), rs11571684 (located at $14.5 \mathrm{~kb}$ downstream; $\left.r^{2}=1.0\right)$, has been analysed in CGEMS. This variant did not show any trend for an association with breast cancer ([AG] vs. $[\mathrm{AA}], \mathrm{OR}=0.79$, $P=0.96)$, thus confirming our results.

\section{Discussion}

Inherited mutations in the $B R C A 1$ and $B R C A 2$ tumour suppressor genes are among the strongest genetic risk factors for breast cancer. According to a world wide study [41], it has 
been estimated that $0.7-29 \%$ of familial heritage are accounted for by mutations in BRCAI, and $1.5-25 \%$ are accounted for by mutations in $B R C A 2$, varying a lot in populations from different geographic regions and ethnicities. Nonsense-, frame shift-, missense-, splice site-, deletion-, insertion-mutations and large deletions/genomic rearrangements have been identified in BRCA1/2 [41-44]. In addition, several non-synonymous SNPs in BRCA1/2 have been associated with breast cancer risk [45-47]. It is crucial to understand the contribution of different types of genetic variants within $B R C A 1 / 2$ to familial breast cancer risk.

Our work is the first study focussing on the possible impact of synonymous SNPs leading to an alteration from the preferred codon-usage in BRCA1 or BRCA2 on familial breast cancer risk. Whereas no obvious codon-usage changing polymorphism could be found in BRCAl, two codon-usage changing SNPs in BRCA2, Ser455Ser $(1365 \mathrm{~A}>\mathrm{G})$ and $\operatorname{Ser} 2414 \operatorname{Ser}(7242 \mathrm{~A}>\mathrm{G})$, were identified and investigated in a large case-control study population. As mutations in BRCA1 and BRCA2 are account for about $30 \%$ of familial breast cancer cases in Germany [8], only BRCA1/2 mutation-negative familial breast cancer cases were included in our study to avoid the effects attributable to disease-associated mutations. Given our sample size, we had a power of $80 \%(\alpha=0.05)$ to detect an OR of 1.64 for Ser455Ser and of 1.30 for Ser2414Ser, not considering the usage of familial cases. The power of an association study based on familial cases is even about two times higher compared to a study of unselected cases [48, 49].

Normally, there is a bias in the use of redundant codons. A comparative study on five mammals for "extreme conservation" showed that there are three times fewer synonymous than non-synonymous mutations [50]. This indicates that synonymous codons are under strong evolutionary selection. Thus, the variation of the codon-usage may result in functional impact. Chava Kimchi-Sarfaty et al. [25] reported a functional synonymous SNP whose rare allele reduces the codon-usage frequency from 20.9 to $15.8 \%$ (ATC-ATT). This results in a delayed translation and changes the folding of the protein. In consequence, this SNP was associated with altered ligand binding efficiency.

The two codon-usage-changing SNPs in BRCA2 introduce an $A-G$ transition in the third base position of a codon for Serine: Ser455Ser (1365A > G) and Ser2414Ser (7242A > G), changing the TCA-codon $(12.2 \%$ usage in Homo sapiens, Table 1) to the less preferred TCG-codon (4.4\% usage in Homo sapiens, Table 1). But here, both variants, Ser455Ser $(1365 \mathrm{~A}>\mathrm{G})$ and $\operatorname{Ser} 2414 \operatorname{Ser}(7242 \mathrm{~A}>\mathrm{G})$, showed no association with familial breast cancer risk.

According to the work of Chava Kimchi-Sarfaty et al. the change from ATC-codon-usage to ATT-codon-usage is only $20.9-15.9 \%$, but nevertheless this specific change alters the drug and inhibitor interactions of P-glycoprotein
$[25,26]$. Therefore, in the present study, although the two investigated SNPs in BRCA2 showed no association with familial breast cancer risk, it is still unknown whether these two SNPs which induced the greatest reduction of preferred codon-usage in Homo sapiens are associated with breast cancer therapy or drug treatment. We also can not exclude the possibility that other synonymous variants found in $B R C A 1$ and BRCA2 showing less codon-usage alternation are associated with breast cancer risk.

Acknowledgments We would like to thank all participants who joined this study. The German breast cancer samples were collected within a project funded by the Deutsche Krebshilfe (Grant number: 107054). This study was supported by the Helmholtz society, the German Cancer Research Center (DKFZ) and the EU, LSHC-CT2004-503465.

\section{References}

1. Parkin DM, Bray F, Ferlay J, Pisani P (2005) Global cancer statistics, 2002. CA Cancer J Clin 55:74-108. doi:10.3322/ canjclin.55.2.74

2. Hopper JL (2001) Genetic epidemiology of female breast cancer. Semin Cancer Biol 11:367-374. doi:10.1006/scbi.2001.0392

3. Narod SA (2002) Modifiers of risk of hereditary breast and ovarian cancer. Nat Rev Cancer 2:113-123. doi:10.1038/nrc726

4. Czene K, Lichtenstein P, Hemminki K (2002) Environmental and heritable causes of cancer among 9.6 million individuals in the Swedish family-cancer database. Int J Cancer 99:260-266. doi: 10.1002/ijc. 10332

5. Lichtenstein P, Holm NV, Verkasalo PK, Iliadou A, Kaprio J, Koskenvuo M, Pukkala E, Skytthe A, Hemminki K (2000) Environmental and heritable factors in the causation of canceranalyses of cohorts of twins from Sweden, Denmark, and Finland. N Engl J Med 343:78-85. doi:10.1056/NEJM200007133430201

6. Hemminki K, Rawal R, Chen B, Bermejo JL (2004) Genetic epidemiology of cancer: from families to heritable genes. Int $\mathrm{J}$ Cancer 111:944-950. doi:10.1002/ijc.20355

7. Pharoah PD, Day NE, Duffy S, Easton DF, Ponder BA (1997) Family history and the risk of breast cancer: a systematic review and meta-analysis. Int $\mathrm{J}$ Cancer 7:800-809. doi:10.1002/ (SICI)1097-0215(19970529)71:5<800::AID-IJC18>3.0.CO;2-B

8. Meindl A (2002) Comprehensive analysis of 989 patients with breast or ovarian cancer provides BRCA1 and BRCA2 mutation profiles and frequencies for the German population. Int J Cancer 97:472-480. doi:10.1002/ijc.1626

9. Miki Y, Swensen J, Shattuck-Eidens D, Futreal PA, Harshman K, Tavtigian S, Liu Q, Cochran C, Bennett LM, Ding W et al (1994) A strong candidate for the breast and ovarian cancer susceptibility gene BRCA1. Science 266:66-71. doi:10.1126/science. 7545954

10. Wooster R, Bignell G, Lancaster J, Swift S, Seal S, Mangion J, Collins N, Gregory S, Gumbs C, Micklem G (1995) Identification of the breast cancer susceptibility gene BRCA2. Nature 378:789792. doi: $10.1038 / 378789 \mathrm{a} 0$

11. Easton DF, Deffenbaugh AM, Pruss D, Frye C, Wenstrup RJ, Allen-Brady K, Tavtigian SV, Monteiro AN, Iversen ES, Couch FJ et al (2007) A systematic genetic assessment of 1, 433 sequence variants of unknown clinical significance in the BRCA1 and BRCA 2 breast cancer-predisposition genes. Am J Hum Genet 81:873-883. doi:10.1086/521032 
12. Wooster R, Weber BL (2003) Breast and ovarian cancer. N Engl J Med 348:2339-2347. doi:10.1056/NEJMra012284

13. Brose MS, Rebbeck TR, Calzone KA, Stopfer JE, Nathanson KL, Weber BL (2002) Cancer risk estimates for BRCA1 mutation carriers identified in a risk evaluation program. J Natl Cancer Inst 94:1365-1372

14. Thompson D, Easton DF (2002) Cancer Incidence in BRCA1 mutation carriers. J Natl Cancer Inst 94:1358-1365

15. Hughes DJ (2008) Use of association studies to define genetic modifiers of breast cancer risk in BRCA1 and BRCA2 mutation carriers. Fam Cancer 7:233-244. doi:10.1007/s10689-008-9181-0

16. Esashi F, Christ N, Gannon J, Liu Y, Hunt T, Jasin M, West SC (2005) CDK-dependent phosphorylation of BRCA2 as a regulatory mechanism for recombinational repair. Nature 434:598-604. doi:10.1038/nature03404

17. Rebbeck TR, Wang Y, Kantoff PW, Krithivas K, Neuhausen SL, Godwin AK, Daly MB, Narod SA, Brunet JS, Vesprini D et al (2001) Modification of BRCA1- and BRCA2-associated breast cancer risk by AIB1 genotype and reproductive history. Cancer Res 61:5420-5424

18. Antoniou AC, Spurdle AB, Sinilnikova OM, Healey S, Pooley KA, Schmutzler RK, Versmold B, Engel C, Meindl A, Arnold N et al (2008) Common breast cancer-predisposition alleles are associated with breast cancer risk in BRCA1 and BRCA2 mutation carriers. Am J Hum Genet 82:937-948. doi:10.1016/ j.ajhg.2008.02.008

19. Duan R, Pak C, Jin P (2007) Single nucleotide polymorphism associated with mature miR-125a alters the processing of primiRNA. Hum Mol Genet 16:1124-1131. doi:10.1093/hmg/ ddm062

20. Wang X, Tomso DJ, Liu X, Bell DA (2005) Single nucleotide polymorphism in transcriptional regulatory regions and expression of environmentally responsive genes. Toxicol Appl Pharmacol 207:84-90. doi:10.1016/j.taap.2004.09.024

21. GuhaThakurta D, Xie T, Anand M, Edwards SW, Li G, Wang SS, Schadt EE (2006) Cis-regulatory variations: a study of SNPs around genes showing cis-linkage in segregating mouse populations. BMC Genomics 7:235. doi:10.1186/1471-2164-7-235

22. Yang R, Frank B, Hemminki K, Bartram CR, Wappenschmidt B, Sutter C, Kiechle M, Bugert P, Schmutzler RK, Arnold N et al (2008) SNPs in ultraconserved elements and familial breast cancer risk. Carcinogenesis 29:351-355. doi:10.1093/carcin/bgm290

23. Fan JB, Chee MS, Gunderson KL (2006) Highly parallel genomic assays. Nat Rev Genet 7:632-644. doi:10.1038/nrg1901

24. Kiyohara C, Yoshimasu K (2007) Genetic polymorphisms in the nucleotide excision repair pathway and lung cancer risk: a metaanalysis. Int J Med Sci 4:59-71

25. Kimchi-Sarfaty C, Oh JM, Kim IW, Sauna ZE, Calcagno AM, Ambudkar SV, Gottesman MM (2007) A "silent" polymorphism in the MDR1 gene changes substrate specificity. Science 315:525-528. doi:10.1126/science. 1135308

26. Sauna ZE, Kimchi-Sarfaty C, Ambudkar SV, Gottesman MM (2007) Silent polymorphisms speak: how they affect pharmacogenomics and the treatment of cancer. Cancer Res 67:96099612. doi:10.1158/0008-5472.CAN-07-2377

27. Jamroziak K, Balcerczak E, Smolewski P, Robey RW, Cebula B, Panczyk M, Kowalczyk M, Szmigielska-Kaplon A, Mirowski M, Bates SE et al (2006) MDR1 (ABCB1) gene polymorphism $\mathrm{C} 3435 \mathrm{~T}$ is associated with P-glycoprotein activity in B-cell chronic lymphocytic leukemia. Pharmacol Rep 58:720-728

28. Liou YJ, Wang YC, Chen JY, Chen ML, Chen TT, Bai YM, Lin CC, Liao DL, Lai IC (2008) The coding-synonymous polymorphism rs1045280 (Ser280Ser) in beta-arrestin 2 (ARRB2) gene is associated with tardive dyskinesia in Chinese patients with schizophrenia. Eur J Neurol 15:1406-1408. doi:10.1111/j.14681331.2008.02316.x
29. Knobe KE, Sjorin E, Ljung RC (2008) Why does the mutation G17736A/Val107Val (silent) in the F9 gene cause mild haemophilia B in five Swedish families? Haemophilia 14:723-728. doi: 10.1111/j.1365-2516.2008.01753.x

30. Komar AA (2007) Genetics SNPs, silent but not invisible. Science 315:466-467. doi:10.1126/science.1138239

31. Brunak S, Engelbrecht J (1996) Protein structure and the sequential structure of mRNA: alpha-helix and beta-sheet signals at the nucleotide level. Proteins 25:237-252. doi:10.1002/ (SICI)1097-0134(199606)25:2<237::AID-PROT9>3.3.CO;2-Y

32. Gupta SK, Majumdar S, Bhattacharya TK, Ghosh TC (2000) Studies on the relationships between the synonymous codon usage and protein secondary structural units. Biochem Biophys Res Commun 269:692-696. doi:10.1006/bbrc.2000.2351

33. Cortazzo P, Cervenansky C, Marin M, Reiss C, Ehrlich R, Deana A (2002) Silent mutations affect in vivo protein folding in Escherichia coli. Biochem Biophys Res Commun 293:537-541. doi:10.1016/S0006-291X(02)00226-7

34. Epstein RJ, Lin K, Tan TW (2000) A functional significance for codon third bases. Gene 245:291-298. doi:10.1016/S0378-1119 (00)00042-1

35. Powell JR, Moriyama EN (1997) Evolution of codon usage bias in Drosophila. Proc Natl Acad Sci USA 94:7784-7790. doi: 10.1073/pnas.94.15.7784

36. Capon F, Allen MH, Ameen M, Burden AD, Tillman D, Barker JN, Trembath RC (2004) A synonymous SNP of the corneodesmosin gene leads to increased mRNA stability and demonstrates association with psoriasis across diverse ethnic groups. Hum Mol Genet 13:2361-2368. doi:10.1093/hmg/ddh273

37. Nielsen KB, Sorensen S, Cartegni L, Corydon TJ, Doktor TK, Schroeder LD, Reinert LS, Elpeleg O, Krainer AR, Gregersen N et al (2007) Seemingly neutral polymorphic variants may confer immunity to splicing-inactivating mutations: a synonymous SNP in exon 5 of MCAD protects from deleterious mutations in a flanking exonic splicing enhancer. Am J Hum Genet 80:416-432. doi:10.1086/511992

38. Burwinkel B, Wirtenberger M, Klaes R, Schmutzler RK, Grzybowska E, Forsti A, Frank B, Bermejo JL, Bugert P, Wappenschmidt B et al (2005) Association of NCOA3 polymorphisms with breast cancer risk. Clin Cancer Res 11:21692174. doi:10.1158/1078-0432.CCR-04-1621

39. Dupont WD, Plummer WD Jr (1998) Power and sample size calculations for studies involving linear regression. Control Clin Trials 19:589-601. doi:10.1016/S0197-2456(98)00037-3

40. Loizidou M, Marcou Y, Anastasiadou V, Newbold R, Hadjisavvas A, Kyriacou K (2007) Contribution of BRCA1 and BRCA2 germline mutations to the incidence of early-onset breast cancer in Cyprus. Clin Genet 71:165-170. doi:10.1111/j.1399-0004. 2007.00747.x

41. Fackenthal JD, Olopade OI (2007) Breast cancer risk associated with BRCA1 and BRCA2 in diverse populations. Nat Rev Cancer 7:937-948. doi:10.1038/nrc2054

42. Hogervorst FB, Nederlof PM, Gille JJ, McElgunn CJ, Grippeling M, Pruntel R, Regnerus R, van Welsem T, van Spaendonk R, Menko FH et al (2003) Large genomic deletions and duplications in the BRCA1 gene identified by a novel quantitative method. Cancer Res 63:1449-1453

43. Anglian Breast Cancer Study Group (2000) Prevalence and penetrance of BRCA1 and BRCA2 mutations in a populationbased series of breast cancer cases. Br J Cancer 83:1301-1308. doi:10.1054/bjoc.2000.1407

44. Roa BB, Boyd AA, Volcik K, Richards CS (1996) Ashkenazi Jewish population frequencies for common mutations in BRCA1 and BRCA2. Nat Genet 14:185-187. doi:10.1038/ng1096-185

45. Palli D, Falchetti M, Masala G, Lupi R, Sera F, Saieva C, D’Amico C, Ceroti M, Rizzolo P, Caligo MA et al (2007) 
Association between the BRCA2 N372H variant and male breast cancer risk: a population-based case-control study in Tuscany Central Italy. BMC Cancer 7:170. doi:10.1186/1471-2407-7-170

46. Johnson N, Fletcher O, Palles C, Rudd M, Webb E, Sellick G, s Silva I, McCormack V, Gibson L, Fraser A et al (2007) Counting potentially functional variants in BRCA1, BRCA2 and ATM predicts breast cancer susceptibility. Hum Mol Genet 16:10511057. doi: $10.1093 / \mathrm{hmg} / \mathrm{ddm} 050$

47. Freedman ML, Penney KL, Stram DO, Le Marchand L, Hirschhorn JN, Kolonel LN, Altshuler D, Henderson BE, Haiman CA (2004) Common variation in BRCA2 and breast cancer risk: a haplotype-based analysis in the Multiethnic Cohort. Hum Mol Genet 13:2431-2441. doi:10.1093/hmg/ddh270

48. Houlston RS, Peto J (2003) The future of association studies of common cancers. Hum Genet 112:434-435

49. Antoniou AC, Easton DF (2003) Polygenic inheritance of breast cancer: implications for design of association studies. Genet Epidemiol 25:190-202. doi:10.1002/gepi.10261

50. Schattner P, Diekhans M (2006) Regions of extreme synonymous codon selection in mammalian genes. Nucleic Acids Res 34:1700-1710. doi:10.1093/nar/gk1095 